Proc. Indian Acad. Sci. (Earth Planet. Sci.), Vol. 101, No. 4, December 1992, pp. 387-401.

(C) Printed in India.

\title{
Critical evaluation and geological correlation of teleseismic phase data from Indian seismological stations
}

\author{
G MOHAN and S S RAI \\ National Geophysical Research Institute, Hyderabad 500007, India \\ MS received 16 March 1992; revised 3 September 1992
}

\begin{abstract}
We evaluated the quality of seismic phase data from Indian seismological stations through the analysis of teleseismic travel times reported during 1976-83 and infer that only WWSSN stations (NDI, SHL, POO, KOD) apart from GBA and HYB can be rated satisfactory while the majority of stations (more than 40 ) produce very poor quality data sets. Detailed analysis of teleseismic P-wave travel time residuals shows that while the average structure of the upper mantle beneath India has high velocity (negative residuals) there are marked lateral variations. In particular, three zones of anomalous positive residuals (low velocity) are observed: one beneath the north western part of the Deccan trap, the second covering the southernmost peninsula (granulite terrain) and a third rather localized one, to the north of Delhi coinciding with Delhi-Haridwar ridge. New Delhi exhibits strong negative residuals in the E-SE quadrant along with negative station anomaly, implying that it is underlain by an anomalous high velocity crust/upper mantle. The negative residuals observed over India, continue beneath the Himalaya till the south of Lhasa but change sign further northward, suggesting the northern limit of the Indian upper mantle structure.
\end{abstract}

Keywords. Phase data; residuals; seismology; teleseisms.

\section{Introduction}

Earthquake phase travel time observations form the single largest data base available to seismologists. The last decade witnessed a dramatic surge in the application of these data sets, at regional and global level, to comprehend 3D seismic images of the earth through "Seismic tomography" (Aki et al 1977) capable of transforming the travel times into $3 \mathrm{D}$ velocity variations. Model resolving capability of the resulting tomograms depends on the data reliability apart from the spatial distribution of sensors and accurate mathematical transformation of earth system into models. It is, therefore, important to test the data quality before searching for meaning into the earth's image. Another area of vital importance-determination of hypocentral parameters to derive seismotectonic framework of the region depends crucially on the data accuracy. In this paper we study the data reliability from Indian seismological stations and attempt to provide a geologic meaning to the observations.

\section{Seismological stations in India}

Indian seismological stations (figure 1) contributing data to the International Seismological Center (ISC) are largely maintained and operated by the India Meteorological Department (IMD) except for HYB and GBA operated by NGRI 


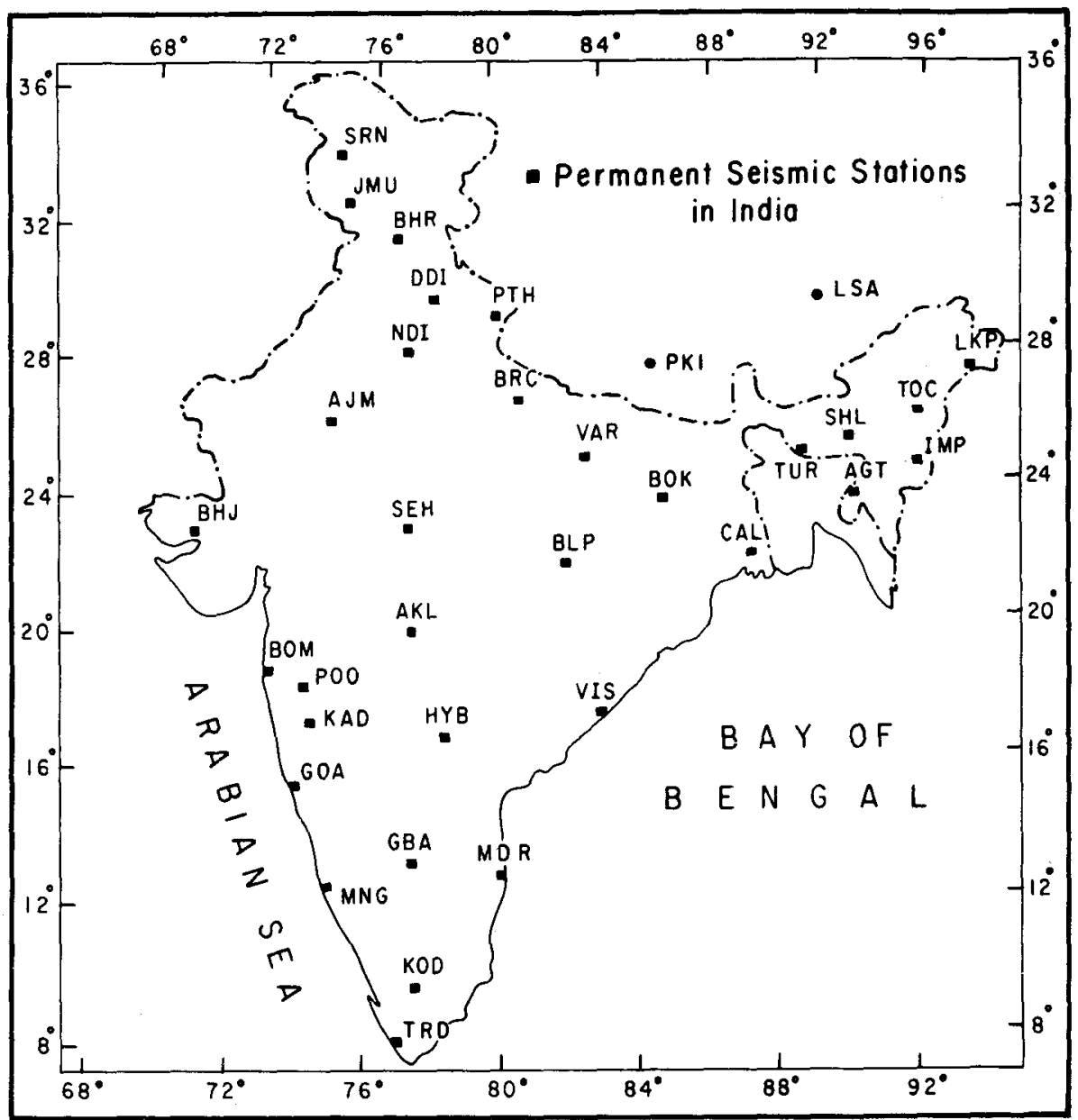

Figure 1. Geographic locations of seismological stations.

(National Geophysical Research Institute) and BARC (Bhaba Atomic Research Centre). The GBA seismic array is a short-period, L-shaped telemetered digital array (20 sensors) with a broad-band, 3-component digital seismograph operating at its crossover point. Seismological stations NDI, SHL, POO, KOD and HYB operate at WWSSN specifications, while the majority of the other stations have fairly mixed operational configuration.

\section{Data analysis}

We scanned the teleseismic phase data (epicentral distance $>20^{\circ}$ ) for the years 1976-83 from the Bulletins of ISC and IMD. The final choice was 900 well-located earthquakes of magnitude $\mathrm{Mb}>5.5$ with errors in latitude and longitude less than $0 \cdot 1$ degree. The stations that reported less than 100 earthquakes were not included in the detailed analysis. The most important component in phase data is the arrival 


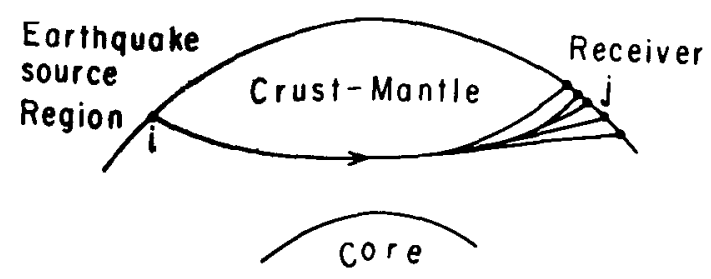

Figure 2. Schematic representation of teleseismic ray path from source to the recording station.

time accuracy. The first arriving $\mathrm{P}$-wave is easiest observable on a seismogram and is widely reported in the phase data bulletins. Seismic phase picking depends on the earthquake magnitude, depth, background noise, wave path (continent/oceanic) etc. To minimize the arrival time reading error we preferred to analyze earthquakes with large magnitudes $\mathbf{M b}>\mathbf{5} .5$. Apart from the source related errors described above, the human factor plays a vital role as seismograms at stations are analyzed by different persons at different times and so an individual's perspective enters into data reliability. The other important component in influencing the data reliability includes timekeeping and operational parameters of the seismograph. All the factors mentioned above jointly make a seismic station good, tolerable, bad or hopeless.

Our mechanism for reliability testing is through the study of travel time residuals (Herrin 1968) pattern at a station. The residual is the difference between the observed and computed (for spherical earth model) travel time for a given $\operatorname{source}(i)-\operatorname{receiver}(j)$ pair (figure 2)

$$
r_{i j}=T^{\infty}-T^{\text {th }}
$$

where $T^{o}$ is the observed travel time and $T^{\text {th }}$ is the computed theoretical travel time.

The residual $r_{i j}$ has contributions from the geologic structure in the vicinity of source and receiver, earthquake origin time and path effect between source and receiver. Incoherent errors also contribute to this. To further reduce the errors due to source effect and any random factor, we compute the residual relative to an "event average"

$$
r r_{i j}=r_{i j}-1 / N \sum r_{i j}
$$

As illustrated in figure 2 the residuals observed at all the stations recording an event, have a common contribution from origin time, hypocentral parameters, inhomogeneities near the source and along the path. These effects could largely be reduced by considering the relative residual. Given a source-receiver geometry, it is unlikely that $r r_{i j}$ would vary significantly from event to event from the same region. However, an average event was computed by averaging all the events and the corresponding residuals in every $2^{0} \times 2^{0}$ source region. This would eliminate any remaining errors associated with the source mislocations. Anomalous fluctuations in residual from the average value is primarily due to the inaccurate phase picking and poor time maintenance. This serves as a measure to study the station quality. The relative residuals greater than \pm 3 seconds at a station are found to be geologically unconvincing and were rejected. This data rejection rate (figure 3 ) is also included to study station quality. 


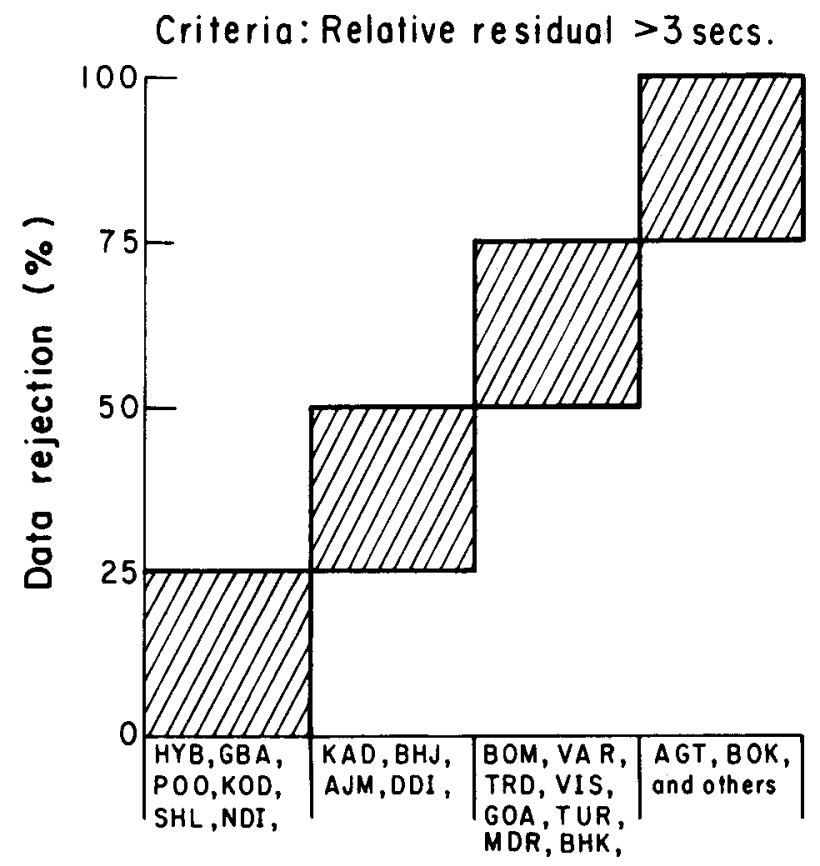

\section{Stations}

Figure 3. Percentage of events with relative residuals $>3 \mathrm{sec}$ at different seismological stations.

Without any further averaging we study the travel time residual pattern at Indian seismological stations. Also we include the data from two nearby stations PKI (Nepal) and LSA (Tibet) for the sake of completeness and comparison. Variation of residual with azimuth for seismic stations is presented in figure 4(a-e). At a first glance the data scatter at individual stations can be quantified from these figures. The stations in figure 4(a), i.e. NDI, SHL, KOD, POO, GBA and HYB have much larger data sets and less scatter in contrast to those in figure 4(b-e). Under the known geological framework of the region peak-to-peak residual variations are unlikely to exceed 1.5-2.0 s. There are exceptions; the stations overlying a tectonically active zone with an abnormally thick crust would show anomalous positive residuals whereas those lying over a stable shield will exhibit negative residuals. The peak-to-peak residual variation in the former case is likely to exceed the limit $1.5-2.0 \mathrm{~s}$. Hence, the stations LSA and PKI overlying an active zone have been corrected for their excess crustal thickness of $15 \mathrm{~km}$ and $30 \mathrm{~km}$ respectively. Percentage of the data set at individual station falling in this category is plotted in figure 5. Analysis of the detailed data set presented in figure 4 along with figures 3 and 5 reveal the following reliability categorization (see table 1) for the Indian seismological stations.

\section{Remarks on station quality}

The present study shows that most of the seismological stations in India generate not very reliable phase data and can help in providing only the gross character of 


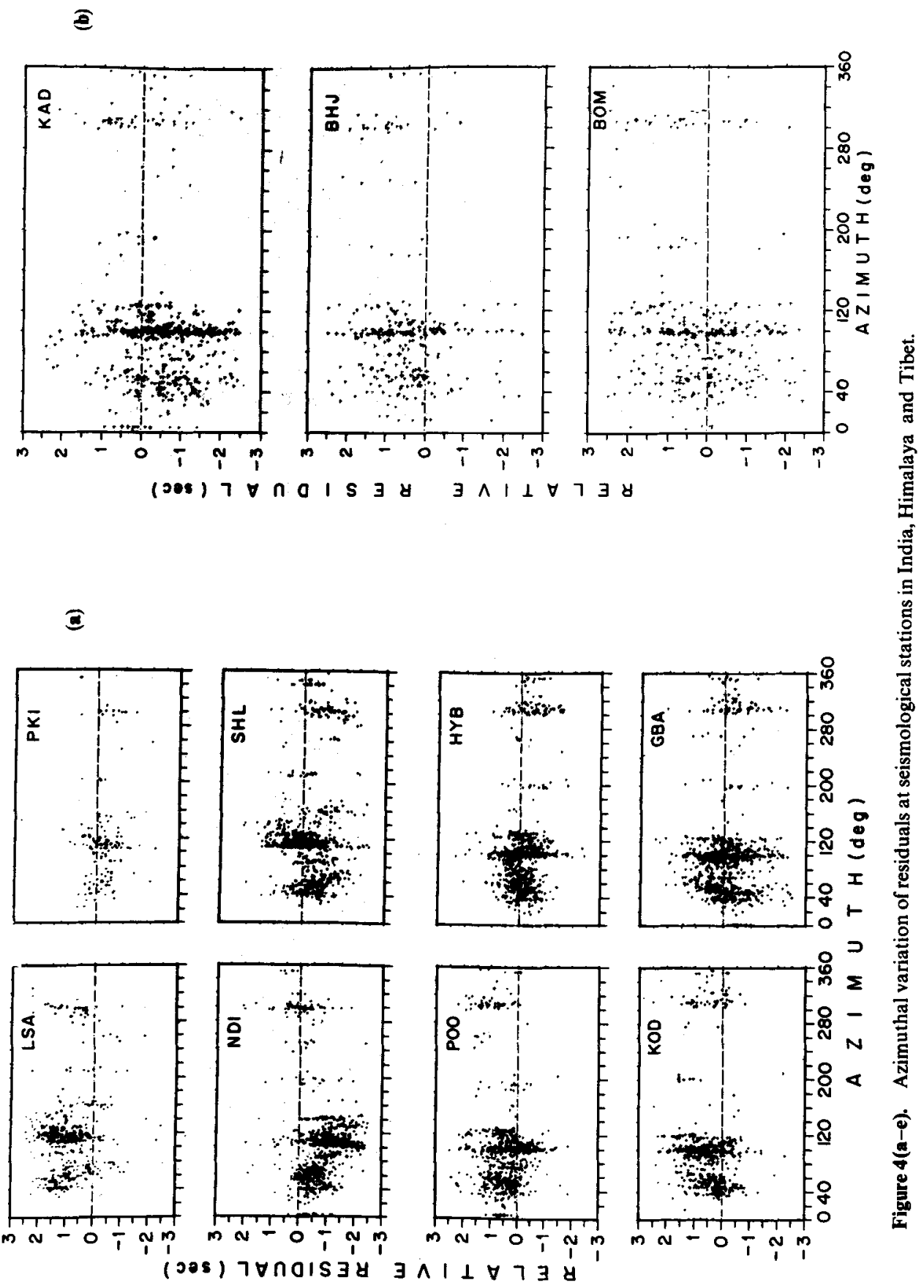



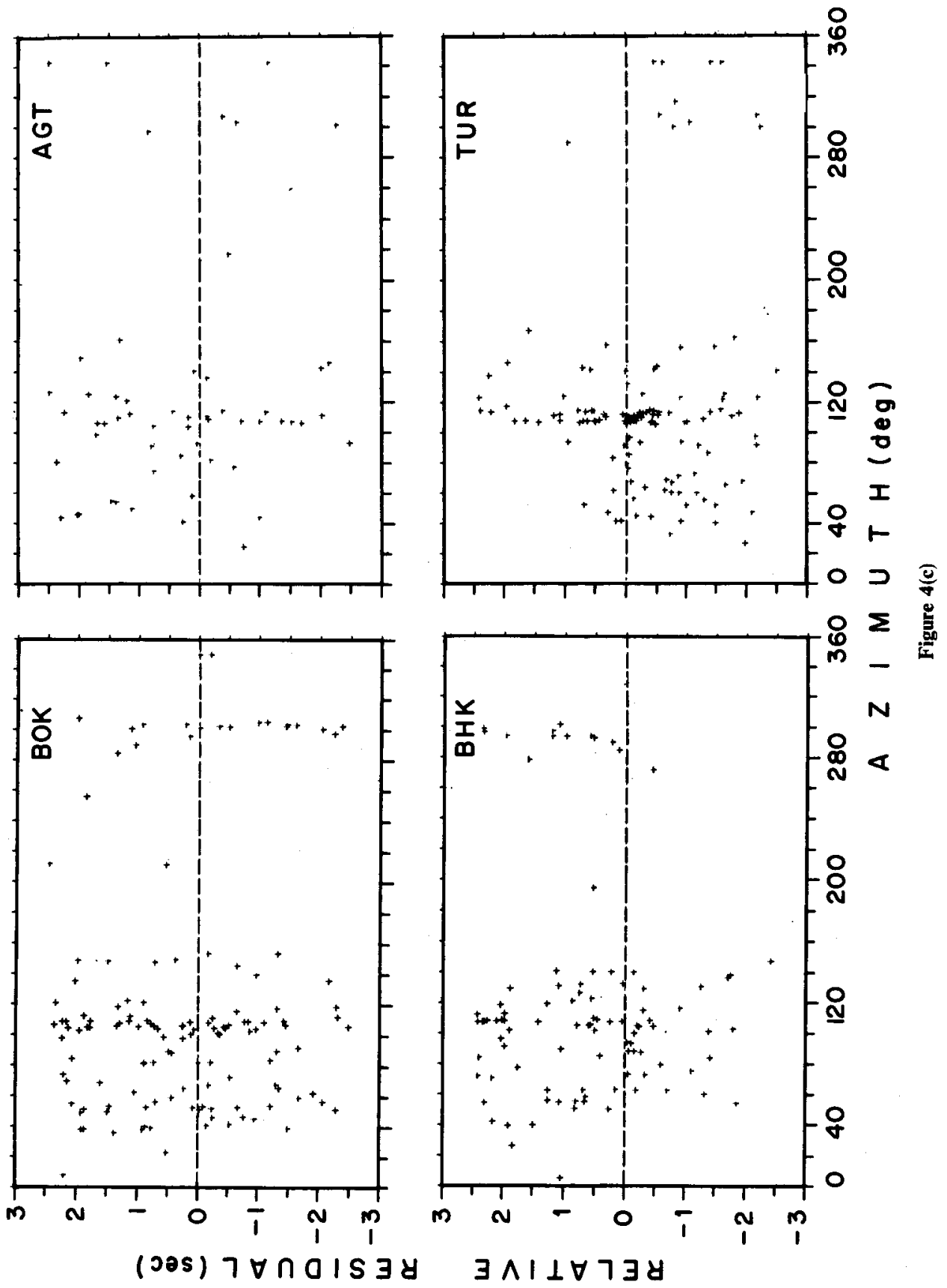

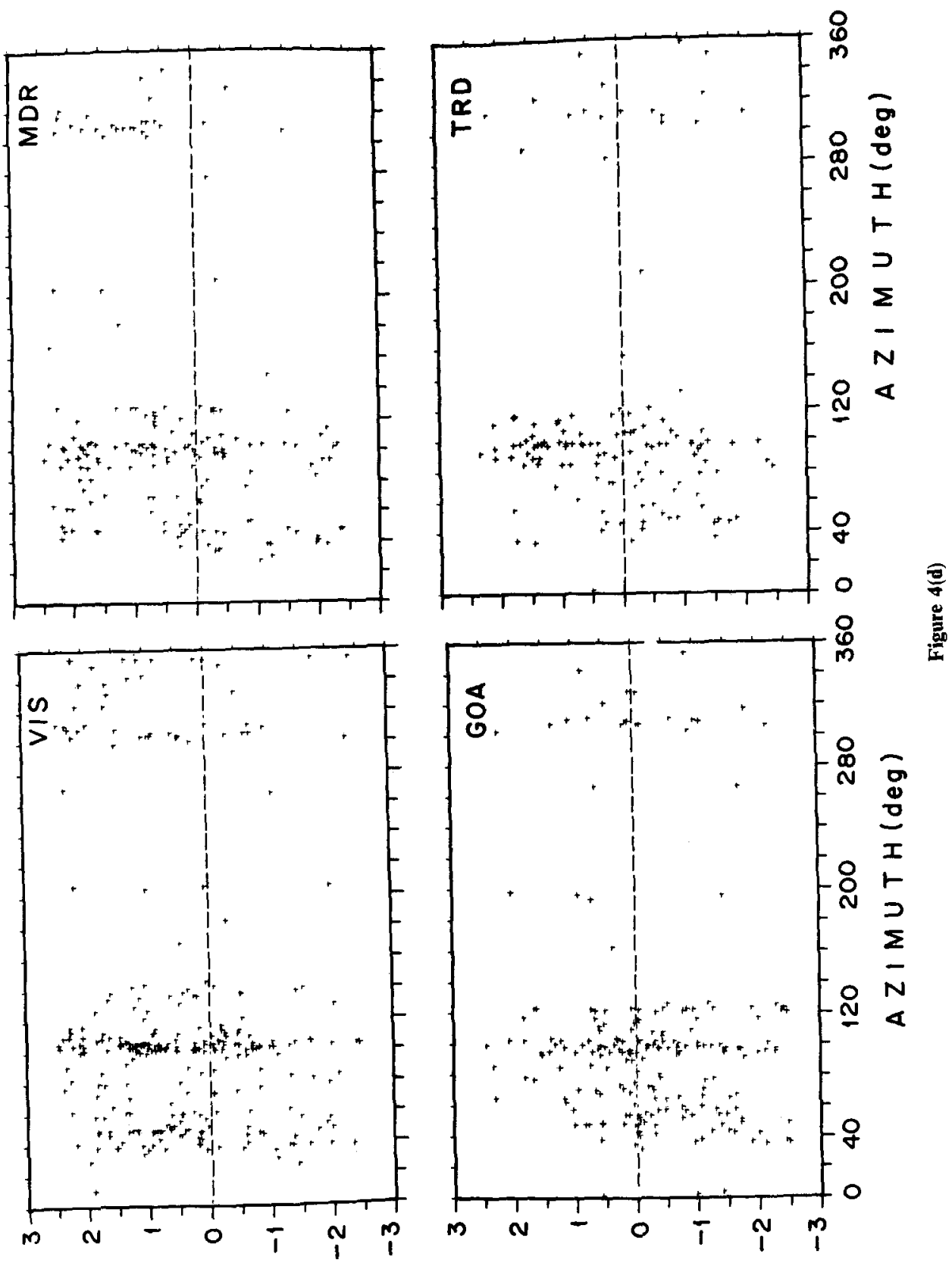

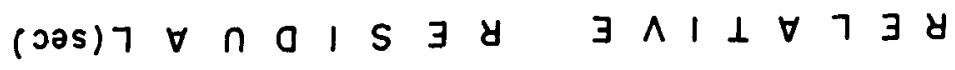




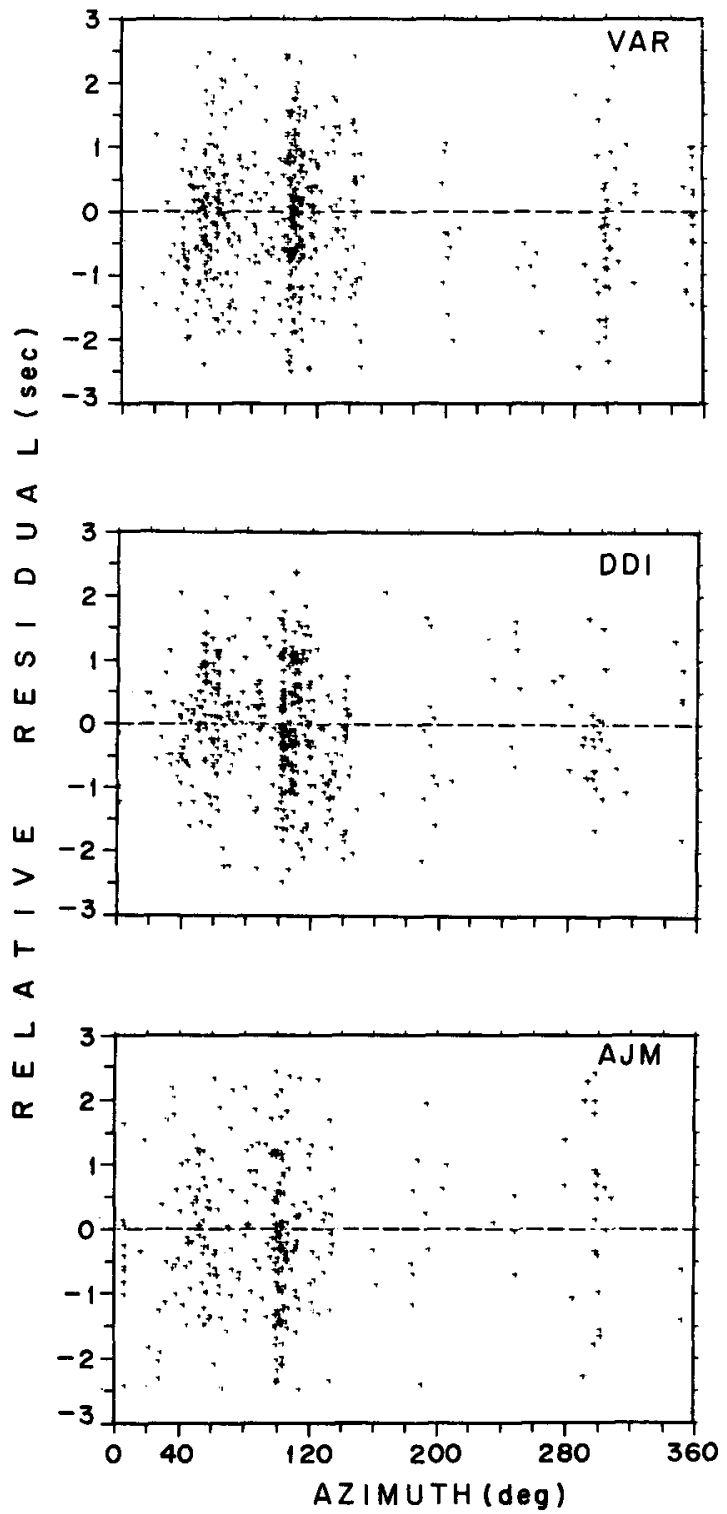

Figure 4(e)

the region. This would be reflected also in the local/regional hypocenter location in this region. Some of the noticeable exceptions to these include WWSSN (NDI, POO, KOD, SHL), HYB and GBA stations. The study only makes a statement of fact realizing that it is an absolute necessity to improve upon the existing scenario to a respectable one. This requirement is urgent from the view point of elucidating geodynamics of the Indian plate, because the Indian plate is a focal point of global geodynamics. However, in the absence of more reliable data sets, the studies in this part of the continent have remained quite hazy. 


\section{Criteria: Peak to peak relative residual $<2$ secs.}

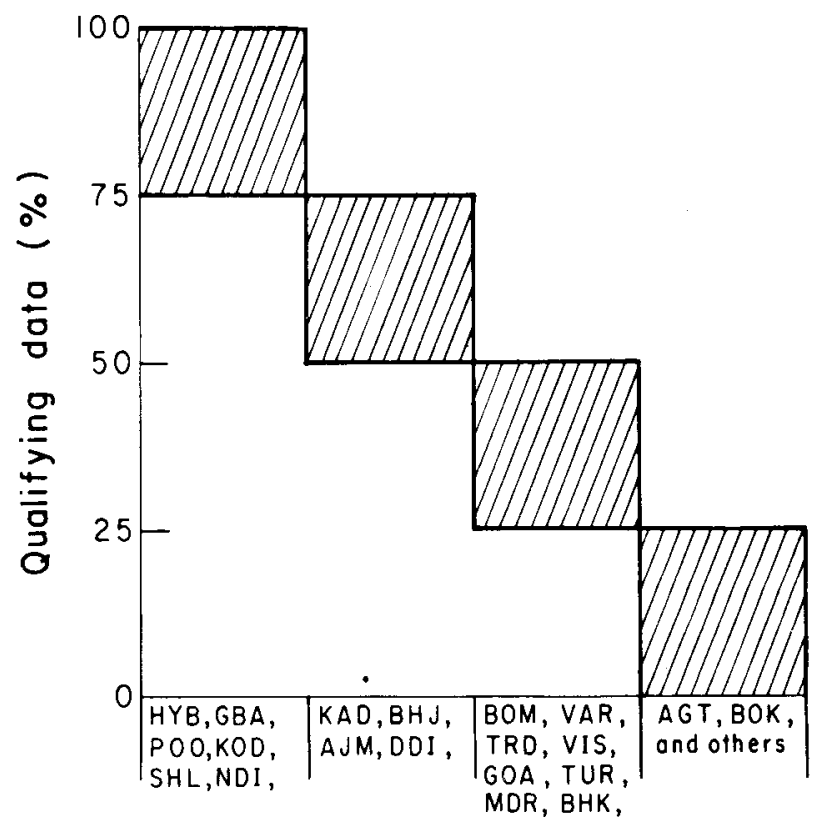

stations

Figure 5. Percentage of events with relative residual (peak to peak) $<2 \mathrm{sec}$ for different seismological stations.

Table 1. Reliability categorization for the Indian seismological stations.

\begin{tabular}{lrrrr}
\hline $\begin{array}{l}\text { Station } \\
\text { quality }\end{array}$ & $\mathrm{N}$ & $\mathrm{d} r(\%)$ & $\mathrm{d} 0(\%)$ & \multicolumn{1}{c}{ Name of the station } \\
\hline Good & $>900$ & $<25$ & $>75$ & HYB, GBA, POO, KOD, SHL, NDI \\
Tolerable & $400-800$ & $25-50$ & $50-75$ & KAD, BHJ, AJM, DDI \\
Bad & $100-400$ & $50-75$ & $25-50$ & $\begin{array}{l}\text { BOM, VAR, MDR, TRD, VIS, GOA, TUR, } \\
\text { BHK }\end{array}$ \\
Hopeless & $<100$ & $>75$ & $<25$ & $\begin{array}{l}\text { AGT, BOK and the rest are shown in } \\
\text { figure } 1 .\end{array}$ \\
& & & &
\end{tabular}

$\mathrm{N}=$ Number of earthquakes with magnitude $\mathrm{Mb}>5.5$ and relative residual $<3.0 \mathrm{~s}$. $\mathrm{d} r=$ Percentage of earthquakes rejected at a station because of relative residual $>3.0 \mathrm{~s}$. $\mathrm{d} 0=$ Percentage of data sets at a station with peak-to-peak relative residuals less than $2 s$ with reference to the mean value.

\section{A brief review of Indian geology}

The Indian subcontinent has a complex geology (figure 6) consisting of rock assemblages of ages ranging from 3.8 by to the present. The region can be divided into three major subregions 1) The peninsular India craton 2) The Indo Gangetic 


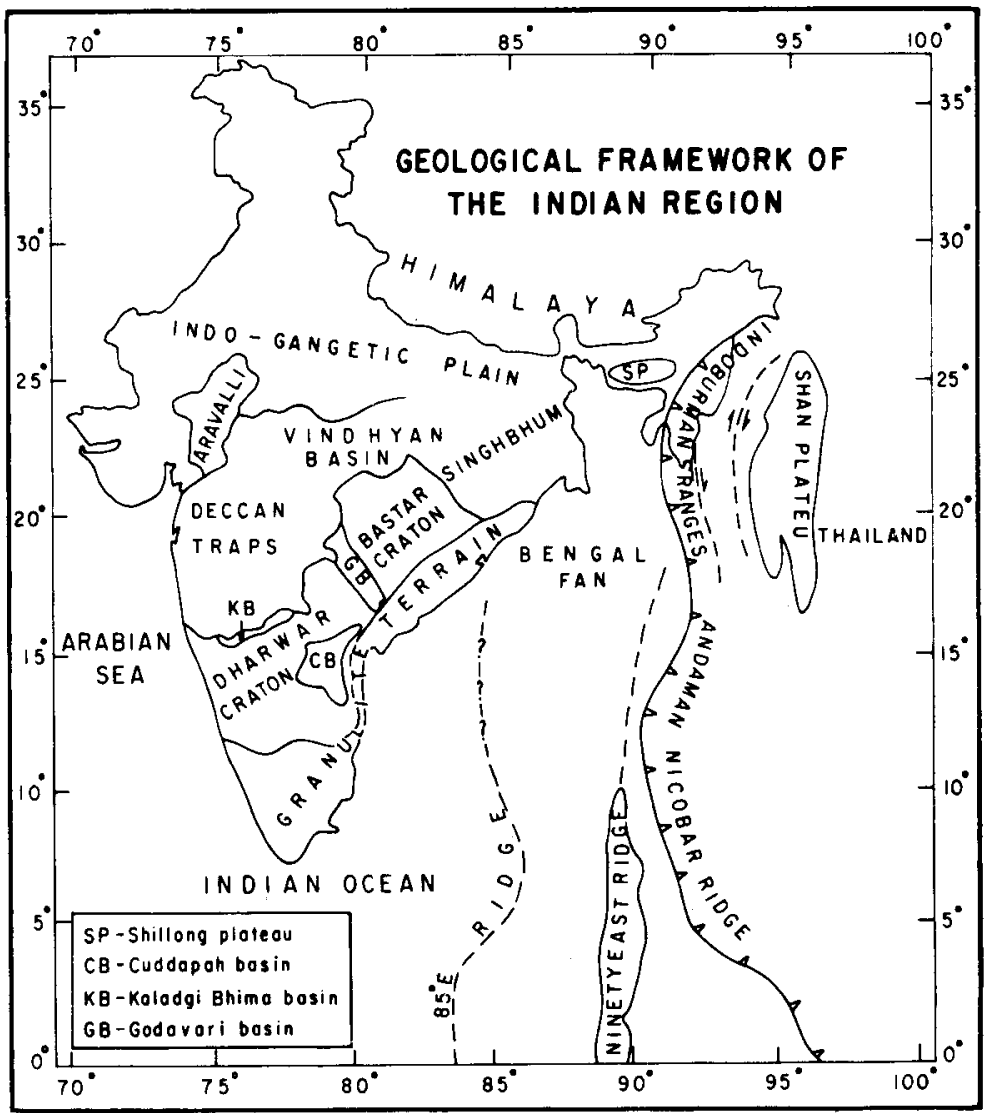

Figure 6. Geological framework of the Indian region.

plain and 3) The Himalayan mountain system. Peninsular India has evolved through the accretion of Archean cratons - Dharwar, Singhbhum, Bastar and Aravalli; intervening mobile belts (Granulite terrains, Delhi, Satpura and Godavari orogenies). The general pattern, nature and deep structures of these mobile belts remain controversial and uncertain. The precambrian terrain is also covered in many areas by sedimentary and volcanic rocks. The sedimentary rock was deposited during Paleozoic and Mesozoic while India was still a part of the Gondwanaland. These terrains include Cuddapah, Godavari and Kaladgi-Bhima apart from the post rifting sedimentary depositions that are restricted to the continental margins. Southernmost and eastern margin of peninsular India comprises of exhumed precambrian metamorphic mobile belt once conjugate with the eastern Antartica in Gondwanaland. Volcanic rocks cover a large part of the peninsular India, with the Deccan traps constituting the largest volcanic flow which erupted around $65 \mathrm{my}$ ago, covering half-million sq $\mathrm{km}$ in the west-central India and a possible equal area in the Arabian sea. Process and place of extrusion of Deccan basalts is a subject of controversy centered around hypotheses related to hotspot, rifting and extraterrestrial effects.

The northern part of the Indian peninsula comprises the Vindhyan (1400-1600 my) sedimentary basin formed due to sedimentation in a pre-existing sea. This basin 
continues underneath the Indo-Gangetic plains and possibly into the Himalayas. To the north-east part of the peninsula lies the Shillong upland plateau comprising of archean gneisses and proterozoic meta-sediments. Mechanism related to the upliftment of the plateau remains intriguing. Northern and eastern extremity of the Indian peninsula consists of the high mountain chains of Himalaya, a consequence of protracted collision of India with Asia over the past $38 \mathrm{my}$. This led to the subduction of the Indian plate in the regions extending from Hindukush-Tibet-Burma. Detailed geological framework of the Indian region (figure 6) is presented in Valdiya (1984), Naqui and Rogers (1987), Molnar (1988) and Verma (1991). The space-time variability of geotectonic history of the Indian region forms an important set of problems in earth sciences. It is a consequence of past and ongoing geodynamic processes, the unravelling of which needs detailed exploration of the lithospheric architecture underneath it.

\section{Upper mantle inhomogeneities beneath India, Himalaya and Tibet}

We attempt to infer, very broadly, the nature of seismically inhomogeneous regions from the analysis of teleseismic P-wave travel times recorded over seismological stations in India, Nepal and Tibet. Over 10,000 teleseismic $\left(25^{\circ}<\Delta<85^{\circ}\right)$ P-wave arrival times from earthquakes of magnitude $\mathrm{Mb}>5 \cdot 5$, recorded at seismic stations marked in figure 1 and reported in ISC (The International Seismological Centre, Newbury) and IMD (The India Meteorological Department, New Delhi) bulletins during 1976-83, were analyzed to study the upper mantle structure in the region. Relative residuals at each station (figure 4) were computed for events originating in various azimuths, with reference to a regional average residual (Romanowicz 1979) for the corresponding event obtained from the 8 most reliable stations LSA, PKI, SHL, NDI, POO, HYB, GBA and KOD duly corrected for station elevation and the earth's ellipticity (Dziewonski and Gilbert 1976). The relative residuals hereafter called "residuals" were computed using Herrin's earth model although the choice of a specific earth model (Jeffreys and Bullen 1958; Herrin 1968; Dziewonski and Anderson 1981) does not influence the inferences. The nonvanishing values of residuals at a station are mainly produced by inhomogeneities in the crust and upper mantle directly underneath.

For Indian stations, contributions from the former, based on an average crustal thickness of $37 \pm 5 \mathrm{~km}$, determined from DSS (Kaila 1982; Kaila and Tewari 1985) and surface wave (Bhattacharya 1974; Lyon-Caen 1986; Singh 1987) studies in different parts of the region, amount to no more than 0.3 s. For Pulchoki (PKI) in NepalHimalaya and Lhasa (LSA) corrections were made for the excess crustal thickness of 15 and $30 \mathrm{~km}$ respectively, inferred from the results of the Franco-Chinese expedition (Allegre et al 1984; Hirn et al 1984a, b). Assuming a crustal velocity of $6.4 \mathrm{~km} / \mathrm{s}$ and $6.5 \mathrm{~km} / \mathrm{s}$ respectively in the deepened crust under PKI and LSA relative to the upper mantle velocity of $8.1 \mathrm{~km} / \mathrm{s}$ beneath India, these corrections were found to be approximately $0.49 \mathrm{~s}$ for PKI and $0.91 \mathrm{~s}$ for LSA.

The existence, broadly, of higher velocity upper mantle in the Indian region, as already stated, is clearly brought out by the station anomalies (Cleary and Hales 1966) computed by averaging residuals for all the events lying in different azimuths and at various epicentral distances within the range considered. The station anomaly 


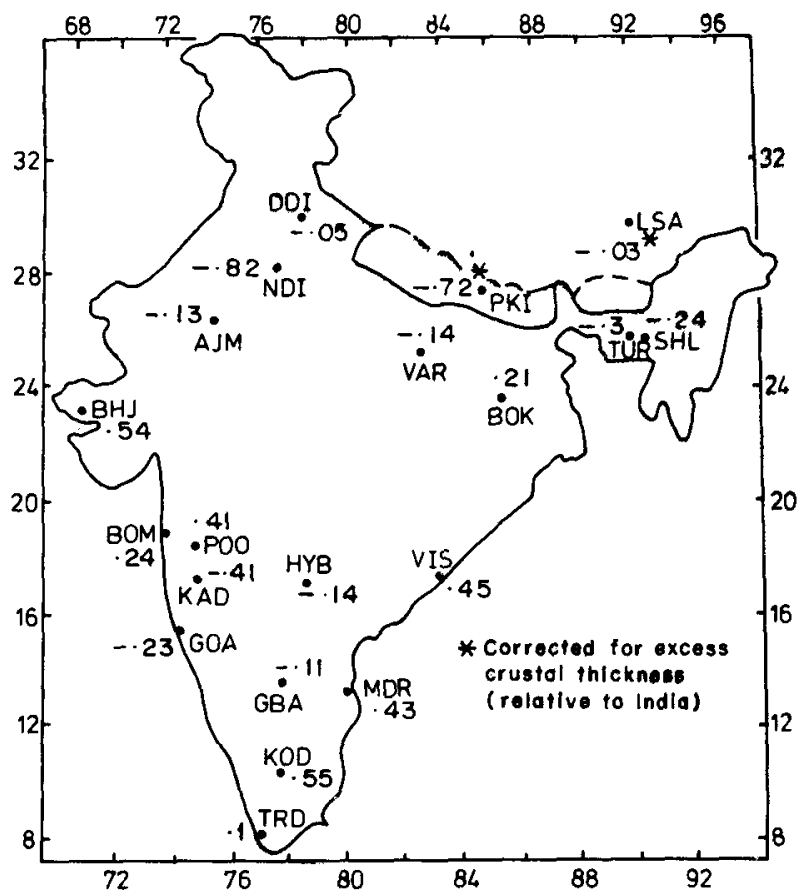

Figure 7. Station anomaly at different seismological stations.

for this region is presented in figure 7 . Variation of residuals with azimuth, however, reveals some interesting details. To study these, residuals have been plotted with azimuths in figure 4(a-e) while sector-wise average computed for consecutive angular widths of $20^{\circ}$ are given for a large number of stations in table 2, using data with rms error $<0.3 \mathrm{~s}$.

Teleseismic $\mathrm{P}$-wave arrivals from all azimuths are uniformly delayed at POO, BOM and $\mathrm{BHJ}$, which are all lying over the Deccan trap, one of the most extensive flood basalt provinces of the world. But the delay at Poona (POO) appears to decrease from $1 \mathrm{~s}$ in W-NW to $0.5 \mathrm{~s}$ in N-NE. At KAD south of POO, the residuals are negative. Considering these observations and the reported presence of a high velocity upper mantle (Srinagesh et al 1989) east of POO, it is inferred that the upper mantle W-NW of POO is a low velocity region.

The other important time-delayed anomaly is observed over the exposed metamorphic terrain of India that continues to the south of $12^{\circ} \mathrm{N}$ forming a linear belt along the easternghat belt. Seismic stations on the granulite belt include KOD, TRD, VIS and MDR. Significant delay in arrival times from all azimuths are also observed at KOD over the southernmost part of the Indian peninsula. However, this delay is reflected only for eastern azimuth at TRD. At KOD the maximum delay is $1-1.35 \mathrm{~s}$ for waves approaching from the S-SE, which is too large to be attributed to any crustal inhomogeneity alone. An average crustal thickness of $38 \mathrm{~km}$ and velocity $6.3 \mathrm{~km} / \mathrm{sec}$ was inferred by Peseckis and Burdick (1982) and Rai et al (1992). Assuming a normal crust of $35 \mathrm{~km}$ thickness, to generate a delay of $1 \mathrm{~s}$ we require the presence of an abnormal crustal thickening of $24 \mathrm{~km}$ or the presence of an unrealistic low velocity crust, about $-15 \%(\mathrm{Vp})$ below $\mathrm{KOD}$, compared to GBA with an average crustal velocity of $6.4 \mathrm{~km} / \mathrm{s}$ and $8.2 \mathrm{~km} / \mathrm{s}$ of upper mantle velocity. Since both the estimates at KOD are unrealistic, we speculate about the existence of a low velocity 


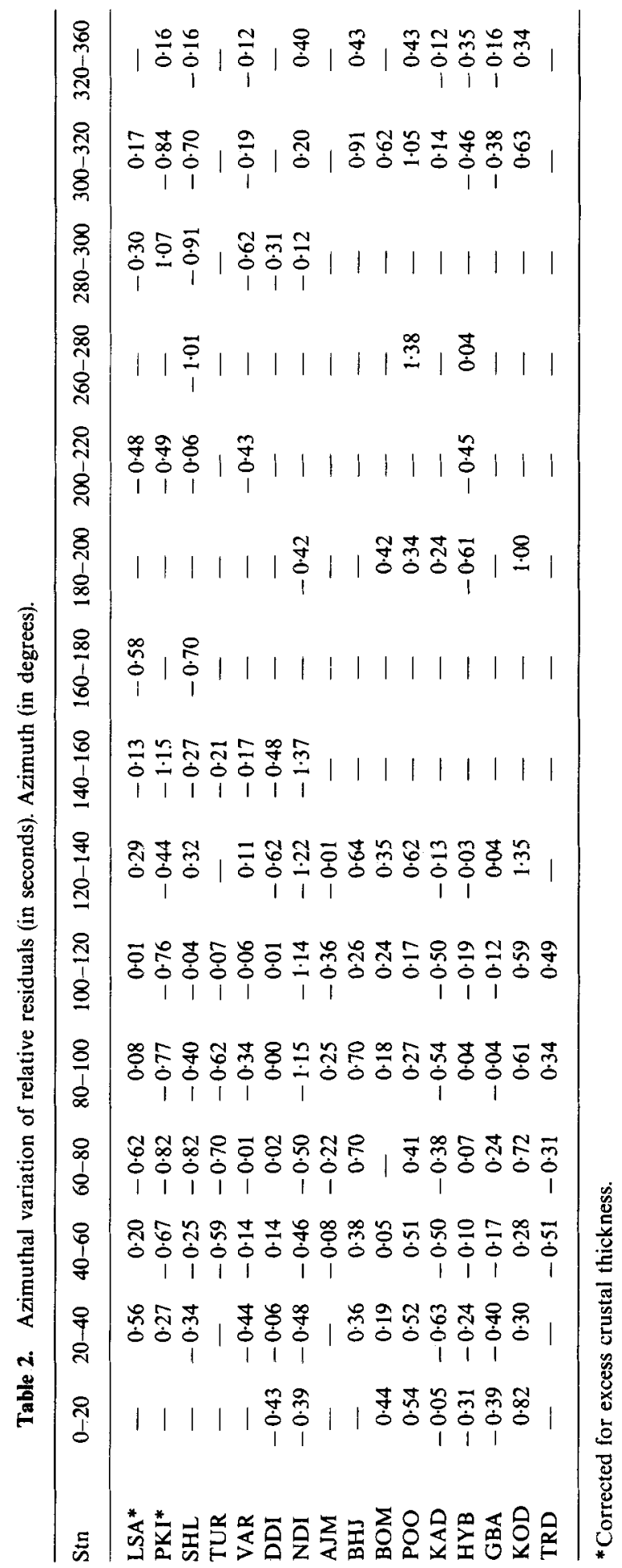


upper mantle underneath a thick low velocity crust. This subcrustal low velocity region is also reflected in the anomalous positive station correction (Dziewonski and Anderson 1983) at KOD and the large gravity low (Qureshy and Warsi 1980), but is perhaps confined to the granulite terrain of south India. For, northward at GBA the residuals are largely negative in respect of southern azimuths $\left(180^{\circ}-200^{\circ}\right)$. Despite poor data quality, the station anomalies at VIS and MDR also show large positive residuals. We, therefore, conclude that the granulite terrains: easternghats and south India, are characterized by significant crustal thickening and low velocity in the upper mantle beneath them. It is remarkable that this precambrian orogenic belt retained the low velocity character for such a long time $(\sim 2.5$ by) apart from crustal thickening and anomalous present day elevation $(2.3 \mathrm{~km})$. We speculate a Himalayan type orogeny in the late Archean to be responsible for thickening and low velocity in the upper mantle beneath the granulite terrain.

A confined positive residual is also observed at New Delhi (NDI) for waves approaching from the NW although in the E-SE quadrant, these have large negative values $(-1.15$ to $-1.37 \mathrm{~s})$. However, at Dehra Dun (DDI), only $225 \mathrm{~km}$ away, the residuals from $\mathrm{NE}-\mathrm{E}$ are close to zero. A short low velocity region $\mathrm{N}-\mathrm{NW}$ of Delhi upto Dehra Dun and continuing further N-NE is thus delineated, coinciding with the Delhi-Haridwar ridge which tears the subducting Indian plate as evidenced by the study of local earthquakes (Gaur et al 1985) and appears to be related to an adjacent deep-seated conductive structure delineated through geomagnetic studies (Arora and Mahashabde 1987). Despite the presence of an approximately $4 \mathrm{~km}$ thick sedimentary column, NDI exhibits a strong negative station anomaly of $(-0.82 \mathrm{~s})$ and large negative residuals $(-1.15$ to $-1.37 \mathrm{~s})$ in the E-SE azimuths. Stripping off the effect of the sedimentary column would result in large negative residuals implying the existence of an anomalous high velocity crust and upper mantle beneath NDI. The northward extension of the Vindhyan basin beneath the Indo-Gangetic plain can explain the observed high anomaly. The ancient Vindhyan sedimentary basin (1400$1600 \mathrm{my}$ ) having an oceanic character owing to its origin by sedimentation in a preexisting sea, would give rise to faster arrivals, resulting in large negative residuals.

The residuals at PKI, duly corrected for the excess crustal thickness, are found to be negative, exhibiting a 'normal' behaviour in common with SHL, VAR and NDI and suggesting the continuation of the Indian upper mantle structure beneath the Himalaya. On the other hand, residuals at LSA show significant azimuthal variation, being positive for NW-NE $(0.17$ to $0.56 \mathrm{~s})$ and negative for SE-SW $(-0.13$ to $-0.58 \mathrm{~s})$. Here, the residual for the northern azimuth is greater than that for the southern, by over $0.9 \mathrm{~s}$ and by 0.5 to $0.9 \mathrm{~s}$ as compared with the nearest Indian station SHL. As no marked crustal differences are known to occur between the region north of Lhasa and that to its south, the above observations, clearly point to a divide in the upper mantle structure beneath Lhasa. We therefore infer that the high velocity Indian lithosphere continues right through the Himalaya to the south of Lhasa, and a lower velocity region in the upper mantle to the north of Lhasa (Molnar and Chen 1984; Jobert et al 1985; Brandon and Romanowicz 1986).

\section{References}

Aki K, Christofferson A and Husebye E S 1977 Determination of the three dimensional structure of the lithosphere; J. Geophys. Res. 82 277-296 
Allegre C J et al 1984 Structure and evolution of the Himalaya-Tibet orogenic belt; Nature (London) 307 17-22

Arora B R and Mahashabde M V 1987 A transverse conductive structure in the northwest Himalaya; Phys. Earth Planet. Int. 45 119-127

Bhattacharya S N 1974 The crust mantle structure of the Indian Peninsula from surface wave dispersion; Geophys. J. R. Astron. Soc. 36 273-283

Brandon C and Romanowicz B 1986 A no lid zone in the central Chang-Thang platform of Tibet: evidence from pure path phase velocity measurements of long period Rayleigh waves; J. Geophys. Res. 91 6547-6564

Bulletin of the International Seismological Centre, 1976-83

Cleary J and Hales A 1966 An analysis of the travel times of P-waves to North American stations in the distance range 30 to 100 ; Bull. Seismol. Soc. Am. 56 467-489

Dziewonski A M and Gilbert F 1976 The effect of small aspherical perturbations as travel times and a reexamination of the corrections for ellipticity; Geophys. J. R. Astron. Soc. 44 7-16

Dziewonski A M and Anderson D L 1981 Preliminary reference earth model; Phys. Earth Planet. Int. $25297-356$

Dziewonski A M and Anderson D L 1983 Travel times and station corrections for P waves at teleseismic distances; J. Geophys. Res. 88 3195-3214

Gaur V K, Chander R, Sarkar I, Khattri K N and Sinvhal H 1985 Seismicity and the state of stress from investigations of local earthquakes in the Kumaon Himalaya; Tectonophysics 118 243-251

Herrin E 1968 Introduction to 1968 seismological tables for P phases; Bull. Seismol. Soc. Am. 58 1193-1241

Hirn A et al 1984a Crustal structure and variability of the Himalayan border of Tibet; Nature (London) 307 23-25

Hirn A et al 1984b Lhasa block and bordering sutures - A contribution of a $500 \mathrm{~km}$ Moho traverse through Tibet; Nature (London) 207 25-27

Jeffreys H and Bullen K E 1958 Seismological tables. British Association for advancement of Science, London

Jobert $\mathrm{N}$ et al 1985 Deep structure of southern Tibet inferred from the dispersion of Rayleigh waves through a long period seismic network; Nature (London) 313 386-388

Kaila K L 1982 Deep seismic sounding studies in India; Bull. Geophys. Res. 20 309-328

Kaila K L and Tewari H C (ed.) 1985 Deep seismic sounding and crustal tectonics; Proc. Int. Symp. on D.S.S traverses 22-24 Nov Bhubaneshwar, India

Lyon-Caen H 1986 Comparison of the upper mantle shear wave velocity structure of the Indian shield and the Tibetan plateau and tectonic implications; Geophys. J. R. Astron. Soc. 86 727-749

Molnar P and Chen W P 1984 S-P travel time residuals and lateral inhomogeneity in the mantle beneath Tibet and the Himalaya; J. Geophys. Res. $896911-6917$

Molnar P 1988 A review of geophysical constraints on the deep structure of the Tibetan plateau. The Himalayas and the Karakorum and their tectonic implications; Philos. Trans. R. Soc. London A326 $33-88$

Naqvi S M and Rogers J J W 1987 Precambrian geology of India. (New York: Oxford Univ. Press) pp 223

Peseckis L L and Burdick L J 1982 Station site characteristics of WWSSN stations in India and southern Asia; Bull. Seismol. Soc. Am. 72 1207-1218

Qureshy M N and Warsi W E K 1980 A bouguer Anomaly map of India and it's relation to broad tectonic elements of the subcontinent; Geophys. J. R. Astron. Soc. 61 235-242

Rai S S et al 1992 Seismic Tomography of the south Indian shield; Curr. Sci. 62 213-226

Romanowicz B A 1979 Seismic structure of the upper mantle beneath the United States by three dimensional inversion of body wave arrival times; Geophys. J. R. Astron. Soc. 57 479-506

Seismological Bulletin India Meteorological department, Division of Seismology, 1976-1983

Singh D D 1987 Crust and upper mantle velocity structure beneath north and central India from the phase and group velocity of Rayleigh and Love waves; Tectonophysics 139 187-203

Srinagesh D et al 1989 Evidence for thick continental roots beneath south Indian shield; Geophys. Res. Lett. 16 1055-1058

Valdiya K S 1984 Aspects of Tectonics: Focus on south central Asia,(New Delhi: Tata McGraw Hill) pp 219

Verma R K 1991 Geodynamics of the Indian peninsula and the Indian plate margin. (New Delhi: Oxford and $\mathrm{IBH}) \mathrm{pp} 356$ 